This item was submitted to Loughborough's Research Repository by the author.

Items in Figshare are protected by copyright, with all rights reserved, unless otherwise indicated.

\title{
Measuring the performance of product introduction
}

PLEASE CITE THE PUBLISHED VERSION

PUBLISHER

(C) IMechE / Professional Engineering Publishing

VERSION

VoR (Version of Record)

LICENCE

CC BY-NC-ND 4.0

REPOSITORY RECORD

Brookes, N.J., and C.J. Backhouse. 2019. "Measuring the Performance of Product Introduction". figshare. https://hdl.handle.net/2134/4580. 
This item was submitted to Loughborough's Institutional Repository (https://dspace.lboro.ac.uk/) by the author and is made available under the following Creative Commons Licence conditions.

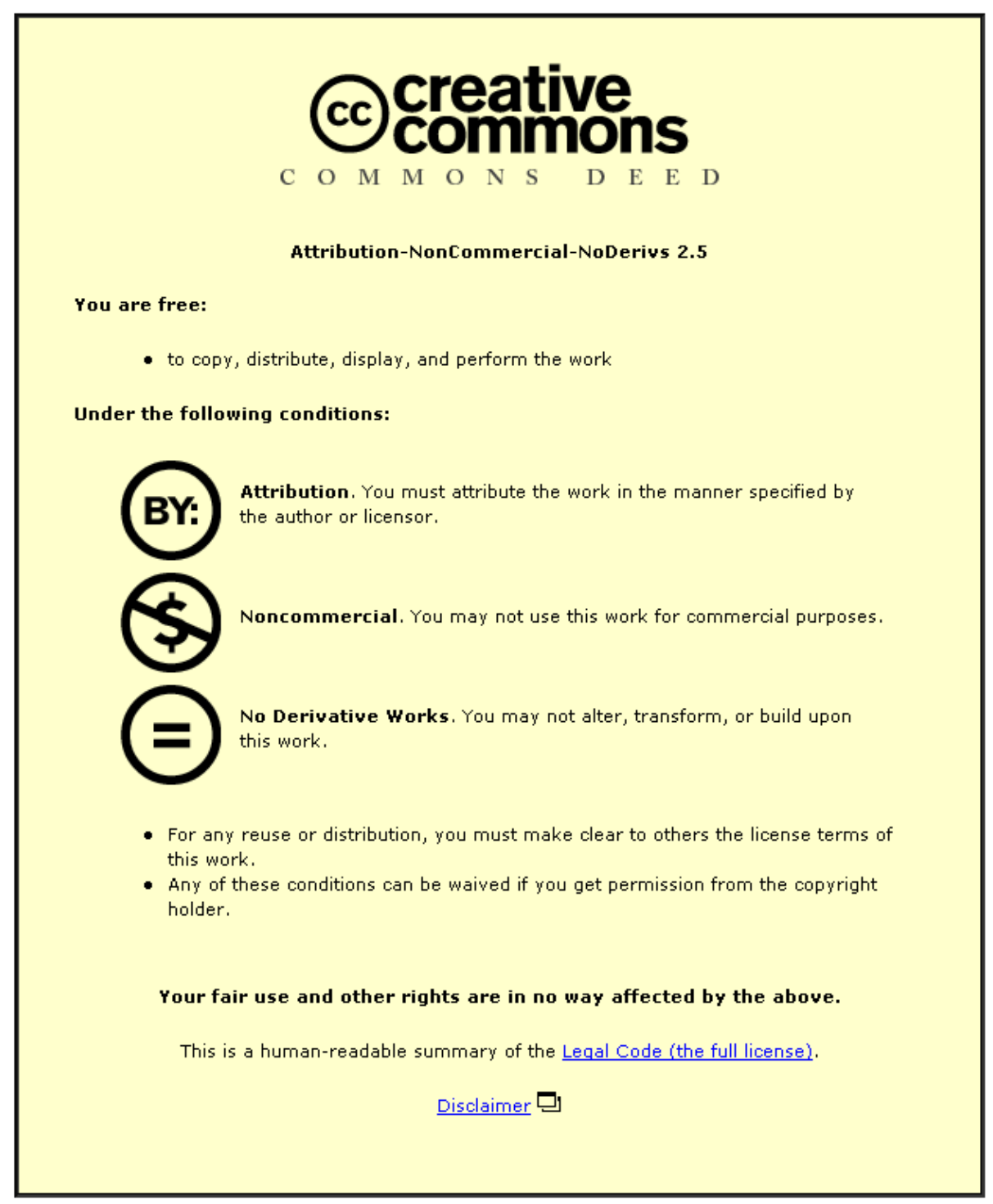

For the full text of this licence, please go to: http://creativecommons.org/licenses/by-nc-nd/2.5/ 


\title{
Measuring the performance of product introduction
}

\author{
N J Brookes and C J Backhouse \\ Department of Manufacturing Engineering, Loughborough University, Leicestershire
}

\begin{abstract}
This paper begins with a discussion of the importance of the effective performance measurement of product introduction and the difficulties inherent within that task. Criteria are then established for effective product introduction performance measures which are used to identify the most appropriate of existing performance measurement mechanisms. A case study approach of industrial organizations is used to examine whether this mechanism is employed in practice, and wider conclusions are drawn on the formation of effective measures of performance for product introduction.
\end{abstract}

Keywords: performance measurement, new product introduction/development

\section{PERFORMANCE MEASUREMENT FOR PRODUCT INTRODUCTION: ISSUES AND PROBLEMS}

\subsection{The importance of effective performance measurement for product introduction}

Performance measurement is recognized widely as one of the key steps in implementing world class manufacturing. Performance measurement's role is not confined to simple reactive monitoring but extends to a proactive mechanism for disseminating strategy and changing organizational culture. Performance measurement plays a vital role in improving companies' competitiveness. To date much work has focused on manufacturing operations. It is equally important to consider applications in other business processes such as product introduction.

It has almost become a cliché to state that companies are now operating in an environment that is changing with increasing rapidity. This has meant that if companies are to survive they must become more adept at reacting to change.

One of the key mechanisms in reacting to this change is better product introduction, i.e. introducing new products more often, more quickly and with a better fit to changing customer requirements. Wheelwright and Clark (1) emphasize the importance of competing through development capability:

In a competitive environment that is global, intense and dynamic, the development of new products and processes increasingly is a focal point of competition.... In a turbulent environment, doing product and process development well has become a requirement for being a player in the competitive

The MS was received on 17 October 1996 and was accepted for publication on 19 August 1997. game; doing development extraordinary well has become a competitive advantage.

As product life-cycles reduce (1), more products need to be introduced more often and hence product introduction becomes more important to business survival. Product introduction shapes the product's characteristics in terms of quality and cost $(\mathbf{2}, \mathbf{3})$. It therefore has a vital role to play in companies' competitiveness in terms of both cost and customer attraction.

With the realization of the importance of product introduction, significant effort has been expended on enhancing its performance. It is the focus of much improvement activity, especially in relation to concurrent engineering. Surveys show that significant numbers of companies using this technique are enjoying benefits (46). If product introduction is a key business process and is the focus of much improvement activity, the derivation of effective performance measures should be crucial. Without these, not only can the operation of product introduction not be managed, but any changes to product introduction to improve its performance cannot be properly evaluated.

\subsection{The difficulties of deriving effective performance measures for product introduction: comparisons with manufacturing operations}

Although effective measurement of the performance of product introduction is important, it is an area of work that is undeveloped, especially when compared to the use of performance measures in manufacturing operations. [The lack of widespread usage of product introduction performance measures found by Bihamni (7) supports this assertion.] In order to understand how this situation has arisen, it is important to understand the relationship between the product introduction process and the manufacturing 


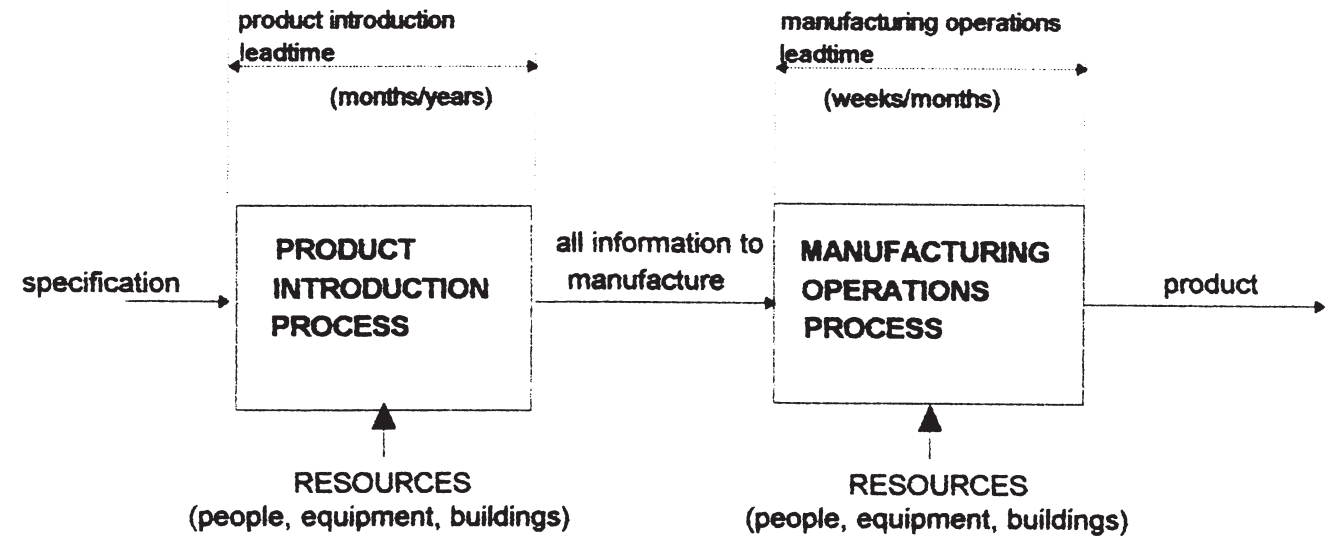

Fig. 1 The relationship between the product and manufacturing operations processes

operations process (see Fig. 1). Product introduction can be considered as a process that converts a product specification into all of the information (in the widest sense of the word), to manufacture that product. The manufacturing operation process takes that information and repeatedly uses it to create a new product. In terms of monitoring product introduction performance, it is comparatively easy to measure the lead-time and the resources used by the process as these have direct parallels with measures used for manufacturing. What is more difficult to measure, though vital if a balanced set of performance measures is to be achieved, is the quality of the product introduction process. Many of the attributes of the manufacturing operations process can be measured directly from the product itself, e.g. its dimensional accuracy or its surface finish. Not only is there something physical to measure at the end of the process, but that measurement is immediately available. This situation is in contrast to that of the product introduction process. The quality of the information produced by it can only be fully assessed when it has been used to manufacture a product. This means that not only must product introduction quality be assessed indirectly, but also that there is a time-lag between producing the output of the process and the measurement of its quality.

The ability to assess process quality is not the only difference between measuring the performance of manufacturing operations and product introduction. Manufacturing performs a virtually similar process many times over. Product introduction involves processes that may be substantially different from one product to another and that, by their very nature, will only be performed once. This means that comparisons of both lead-time, resource and quality will be easier in manufacturing operations than in a product introduction environment. In manufacturing operations it will be possible to compare 'like with like' and also to generate statistically significant samples. In the product introduction environment comparisons between separate product introductions will always be clouded by the fact that it is not the same product that is being introduced. The ability to make comparisons using performance measures is essential in producing performance measures that promote performance improvement. It is likely to be more difficult to define measures that provide this in a product introduction environment.

Table 1 summarizes the differences between measuring performance in a manufacturing operations environment and measuring performance in the product introduction environment. Given these difficulties, it is not surprising that the field of performance measurement for product introduction remains comparatively underexploited.

\subsection{Defining the problems}

This paper has so far discussed the importance of effectively measuring the performance of product introduction and the difficulties inherent in trying to do this, especially when compared to the field of manufacturing operations. Against this background it is important to establish effective and practical mechanisms to successfully measure product introduction. In order to progress to this goal, this paper addresses a series of questions:

1. What criteria should be used to evaluate alternative mechanisms for measuring the performance of product introduction?

Table 1 The differences in performance measurement of the product introduction and manufacturing operation process

\begin{tabular}{lll}
\hline & $\begin{array}{c}\text { Manufacturing } \\
\text { operations }\end{array}$ & $\begin{array}{c}\text { Product } \\
\text { introduction }\end{array}$ \\
\hline $\begin{array}{c}\text { Similarity between } \\
\text { processes }\end{array}$ & Very similar & Dissimilar \\
$\begin{array}{c}\text { Number of times process } \\
\text { performed }\end{array}$ & Many times & Once \\
$\begin{array}{c}\text { Time-lag for measuring } \\
\text { output }\end{array}$ & Weeks & Years \\
$\begin{array}{c}\text { Ability to measure output } \\
\text { quality }\end{array}$ & $\begin{array}{c}\text { Directly } \\
\text { measurable }\end{array}$ & $\begin{array}{c}\text { Indirectly } \\
\text { measurable }\end{array}$ \\
\hline
\end{tabular}


2. Which is the most appropriate of existing mechanisms when evaluated against these criteria?

3. Is this mechanism being practically implemented? If not, why not?

By examining these questions, conclusions have been drawn on the way ahead for practical and effective mechanisms to measure the performance of product introduction.

\section{ESTABLISHING THE CRITERIA TO EVALUATE MECHANISMS FOR PERFORMANCE MEASUREMENT OF PRODUCT INTRODUCTION}

\subsection{Establishing the criteria}

The first stage in establishing criteria to evaluate product introduction performance measures was to identify the characteristics that made generic performance measures effective. This was achieved using existing work in this area. The requirements for effective measurements were then translated into evaluation criteria specific to product introduction.

\subsection{What are the characteristics of effective performance measurements?}

Neely et al. (8) produced an extensive review of literature in the area of effective performance measurements. They reported on the following themes for effective measurements:

1. They should relate to strategy and business processes.

2. They should be simple and relevant.

3. They should be influenced by the user.

4. They should foster an attitude of improvement and not just monitoring.

It can be argued that these are not the only factors that contribute to effectiveness in performance measures for product introduction. In any process, performance improvements can be achieved in some areas to the detriment of others. For example, lead-time can be reduced at the expense of quality. Effective performance measurement cannot rely on a single factor but needs to provide what Kaplan and Norton (9) have called (at a higher level of company operations) a 'balanced scorecard'.

Existing work indicated that effective performance measures needed to monitor today's performance and to show how to improve performance for tomorrow and they needed to do this in a way that was relevant and at the right level for the user. The measurements also needed to be balanced to avoid any dangers of suboptimization.

\subsection{Translating the requirements of effective performance measurement to evaluation criteria for product introduction}

In order to translate these requirements for product introduction, it was first necessary to consider who will be using product introduction measures and what they would be using them for. Product introduction performance measures will primarily be used by project managers responsible for a particular product introduction and by the executive body to whom the project managers report. The purpose of the measures of performance will be twofold:

(a) to insure that the product is introduced reliably (i.e. on time, to specification and to budget);

(b) to promote improvement of the product introduction process.

The operation of the type of performance measurements outlined above lies at a comparatively high level within the organization. It is a fairly straightforward activity to relate these to both a product strategy (as the introduction of a product should directly result from a product strategy) and to a business process (as product introduction itself is a business process). To be relevant, performance measures will need to be set at a whole process level, e.g. overall lead-time and overall resource expenditure. This, of course, does not preclude the project manager breaking these down further as part of his or her project management activity.

'Balance' in terms of product introduction arguably means simultaneously monitoring three categories:

(a) lead-time of product introduction,

(b) resources consumed by product introduction,

(c) quality of product introduction output.

The first two categories are comparatively self-explanatory, the third category may require some expansion. This immediately raises the issue of the ability to directly measure the quality of product introduction that was discussed in the first section of this paper.

In order to foster the improvement of the product introduction process, the performance of different product introductions will need to be compared with each other. Performance measures of product introduction will therefore need to be expressed in a way that allows cross-product comparison.

In summary, the criteria used to evaluate alternative mechanisms for measuring the performance of product introduction are given below:

1. The level of the performance measurement-mechanisms should give results at the 'whole process' level.

2. The balance of performance measurement-mechanisms should incorporate measurements of lead-time, resource and quality. 
3. Ease of comparison of performance measurementmechanisms should facilitate comparisons across different product introductions.

\section{AN EVALUATION OF EXISTING WORK ON PERFORMANCE MEASUREMENT FOR PRODUCT INTRODUCTION}

\subsection{Existing work on performance measurement for product introduction}

Existing work on performance measurement for product introduction can be grouped into a number of sources:

(a) studies into successful product introduction,

(b) 'time' measures,

(c) performance measure lists,

(d) integrated performance measurement.

\subsubsection{Successful product introduction studies}

For many years, work has been undertaken to understand what makes product introduction successful. Implicit within this undertaking is the measurement of performance of product introduction. The approach taken to measuring successful product introduction is interesting. Many researchers in this field determine the success of introducing a new product by simply asking the individuals in the companies studied if they felt that a particular product introduction had been successful and ranked the result on a Likert scale. Examples of this approach can be found in Hise et al. (10), Cooper (11), Ayal and Raban (12) and Weisenfeld-Schenk (13). While this approach may be as valid as any other in judging overall success, what it does preclude is a more detailed understanding of what success is. It does not provide the balance or sufficient detail on monitoring or improving performance that effective performance measures would require. More recently Cooper and Kleinschmidt (14) have attempted to derive more qualitative measures, but these were designed to operate at a macro level and still largely depended on the use of Likert scales.

\subsection{2 'Time' measures}

Time-to-market is a long-established measure of product introduction performance [see, for example, reference (15)]. Time has been recognized as important across a range of business processes $(\mathbf{1 6}, \mathbf{1 7})$ and has been identified as a parameter of prime importance for product introduction [see, for example, references (18-22)]. Getting a product to market before its competitors is seen as a key strategy in that product's successful introduction. Much of the work that stresses time as a measure of performance for product introduction fails to balance it with other performance measures.

\subsubsection{Performance measurement lists}

Many exponents have put forward a list of performance measures that concentrate not only on time but on many aspects of product introduction. Gregory (23), for example, lists the following as performance measures for product introduction used by Hewlett-Packard:

(a) overall measures - break-even time for project;

(b) detailed measures - performance to commitment; marketing system support; post-release support; engineering work-force.

Greater detail on this is provided by House and Price (24). Similarly, a DTI guide (25) recommends the use of the following performance measures:

Time-to-market measures

Average concept to launch time

Time for each phase

Average overrun, per cent of projects overrunning

Average time between product redesigns

Product performance measures

Product cost

Technical performance

Quality

Return on sales

Market share

Design performance

Manufacturing cost

Manufacturability

Testability

Although these performance measurements are balanced in that they concentrate on more than one aspect, they do not link these together in a framework to assist in performance improvement.

\subsubsection{Integrated measurements}

A major theme in work on performance measurements has been the need to accommodate individual measurements into a framework that provides the balance required from an effective set of performance measures. Such approaches have been put forward by Cross and Lynch (26), Kaplan and Norton (9) and Dixon et al. (27). These, however, have concentrated at the macrolevel of business operations and have not specifically addressed the product introduction process. Arguably, the most comprehensive step in linking measures of performance to an overall framework of product introduction is provided by the work of Clark and Fujimoto (28) and Wheelwright and Clark (1). They have evaluated product introduction performance in the following categories:

(a) total product quality - an index to evaluate 'design quality' and 'conformance quality';

B09096 (C) IMechE 1998 
(b) lead-time-for the overall process and for individual stages;

(c) productivity - in engineering hours.

Focusing on the automobile industry allowed them to create definitions and make meaningful comparisons. In order to make comparisons their sample was divided into 'volume producers' and 'high-end specialists'. This approach has been extended to the electronics industry (29).

\subsection{An evaluation of existing work on performance measurements for product introduction}

The criteria developed for performance measures for product introduction at the beginning of this paper stated that the measures needed:

(a) to be balanced, especially in including the quality of the process;

(b) to allow comparisons and hence to promote continuous improvement;

(c) to operate at the right level.

Each of the approaches to the performance measurement of product introduction delineated above can be considered against these.

\subsubsection{Successful product introduction studies}

The approach adopted by studies of successful product introduction operates at a whole process level and achieves balance. However, this is achieved by having a singular measurement of product introduction success that masks some of the detail that may be relevant to the project manager. Furthermore, this measurement transgresses a fundamental of process measurement in that it is a subjective and not an objective measure. Although these studies make a point of comparison, little attempt has been made to ensure that valid comparisons have been made in terms of the product to be introduced.

\subsubsection{Time measures}

Time measures are by their very nature unbalanced as they focus upon only one category of performance measurement. Although lead-time is a measurement at an appropriate level for product introduction, the lack of balance in this approach is likely to make it less effective and, in some cases, dangerous. Utterback et al. (30), Crawford (31) and von Braun (32) highlight this possibility.

\subsubsection{Performance measurement lists}

Performance measurement lists do, on first glance, appear over the range of categories required to give balance to their approach to performance measurement. However, these seem to be created on a somewhat ad hoc basis and no underlying framework is used to relate them. A similar difficulty is seen in terms of the level at which they operate.
Operational-level process measurements appear to be considered with those that are appropriate at a 'whole process' level. In general, no attempt is made with performance lists to show how these can be used for meaningful comparisons.

\subsubsection{Integrated performance measurements}

Integrated performance measures, especially the work of Clark and Fujimoto (28), appear to offer performance measures that operate at a 'whole-process' level and achieve balance in terms of the categories that they use. Alone among the performance measurement approaches considered, they do attempt to make meaningful comparisons between types of product introduction (e.g. their splitting of 'volume' and 'high-end specialists').

The approach that appears to most effectively fulfil the criteria established in the previous section is the integrated measurement approach embodied by Clark and Fujimoto. These measurements do go some way to easing the theoretical difficulties highlighted in the first section. However, it must be remembered that the measurement exercise that Clark and Fujimoto undertook was a 'one-off' retrospective: although they had designed effective measures of performance they did not create an on-going measurement system.

\section{WHAT PERFORMANCE MECHANISMS ARE BEING PRACTICALLY IMPLEMENTED?}

\subsection{The case study methology}

So far, criteria have been established for the selection of the most appropriate mechanism for measuring the performance of product introduction and existing mechanisms have been examined to identify that which most closely fulfils these criteria. The mechanism identified was the 'integrated measurement approach' developed by Clark and Fujimoto (28). An industrial perspective was sought to examine whether similar mechanisms were being used in practice and the reasons that lay behind the adoption (or lack of adoption) of this sort of approach to product introduction performance measurement.

As in all research of this type there is always a dilemma to be faced when choosing a research approach. Often the choice needs to be made between a wider applicability of findings and greater and more meaningful detail. The situation is summarized usefully by Johnson and Gill's (33) matrix for research strategy. Given the exploratory nature of the problem, it was decided not to pursue analytical surveys, but instead to concentrate on a case study approach with a small sample size. (Gill and Johnson quote Mintzberg who says that small samples, especially in exploratory work, should be encouraged rather than less valid data that may give the impression of being more statistically significant.) The case studies were conducted by holding semi-structured interviews with senior engineering executives. The results of the interviews were returned to and checked by 
interviewees. The discussions on performance measurements used Clark and Fujimoto's framework of time, resource, quality and also asked about using these measurements at an individual and aggregate level to make comparisons between projects. The choice of the five companies was to a certain degree directed by those who were willing to commit the time necessary. As wide applicability of the result of the study had already been compromised to a degree by the choice of the case study approach, it was not felt that this would be inimical to the study as a whole. Furthermore, the five companies surveyed represented a wide spread in terms of size and product type.

\subsection{Summary of the case study results}

The Appendix contains details of the results of each of the case studies. All of the case study companies produced performance measurements at a 'whole-process' level. However, these were, without exception, broken down into lower levels. The balance of performance measures for individual product introductions is summarized in Table 2. None of the companies made comparisons between the performance of individual product introductions.

The following themes emerge from these case study experiences.

\subsubsection{Companies measure lead-time and expenditure}

All of the companies measured lead-time and expenditure on individual product introductions. However, these data were often held manually and several companies expressed concerns about its reliability, especially in terms of work booking disciplines.

\subsubsection{The lack of measurement of quality of product introduction}

The quality of the outcome of product introduction was frequently not measured or, if it was measured, it was not related to a particular product introduction. Measurements of process quality that are made appear to be measured in terms of product cost, warranties or customer satisfaction.

\subsubsection{The lack of comparisons of measures of performance across product introductions}

The reasons given for not making these comparisons fall into two categories:

1. It would be too resource-intensive to perform (e.g. the difficulty of accessing manual records, the difficulty of allocating pooled information to particular product introductions).

2. The results would be spurious. (This is either because the data are unreliable or because it is felt impossible to make comparisons across individual product introductions because of their varying nature.)

It is interesting to note that the latter explanation was only provided by two of the companies. The remaining three actually used the case study investigation to trigger oneoff comparison exercises. This difference does not appear to be supported by the type of product or operating environment of the company and suggests a more implicit cultural factor at play.

Table 2 Individual product introduction performance measures in the case study companies

\begin{tabular}{|c|c|c|c|}
\hline & Time & Cost & Quality \\
\hline $\begin{array}{l}\text { Company A } \\
\text { (SME producing } \\
\text { large capitial } \\
\text { equipment) }\end{array}$ & Automated project planning & $\begin{array}{l}\text { Automated work booking of } \\
\text { hours }\end{array}$ & Not measured \\
\hline $\begin{array}{l}\text { Company B } \\
\text { (SME producing } \\
\text { materials handling } \\
\text { devices) }\end{array}$ & $\begin{array}{l}\text { Manual recording against } \\
\text { project plan }\end{array}$ & $\begin{array}{l}\text { Automated recording of materials } \\
\text { and man-hours }\end{array}$ & $\begin{array}{l}\text { Warranty returns measured but not against } \\
\text { individual products }\end{array}$ \\
\hline $\begin{array}{l}\text { Company } \mathrm{C} \\
\text { (SME producing } \\
\text { train brakes) }\end{array}$ & $\begin{array}{l}\text { Manual recording against } \\
\text { project plan }\end{array}$ & $\begin{array}{l}\text { Manual recording of man-hours } \\
\text { and other expenditure }\end{array}$ & Not measured \\
\hline $\begin{array}{l}\text { Company D } \\
\text { (SME producing } \\
\text { materials testing } \\
\text { equipment) }\end{array}$ & $\begin{array}{l}\text { Lead-time by automated } \\
\text { project planning }\end{array}$ & Automated work booking system & $\begin{array}{l}\text { Measured in terms of reaching a 'target cost'; } \\
\text { 'voice-of-the-customer' campaigns } \\
\text { undertaken but not fed back to individual } \\
\text { projects }\end{array}$ \\
\hline $\begin{array}{l}\text { Company E } \\
\text { (large automotive } \\
\text { company) }\end{array}$ & $\begin{array}{l}\text { Lead-time by automated } \\
\text { project planning }\end{array}$ & $\begin{array}{l}\text { Some cost measured by work } \\
\text { booking system but not all } \\
\text { allocated to project and capi- } \\
\text { tal spending }\end{array}$ & $\begin{array}{l}\text { Measured in terms of a target cost; other } \\
\text { customer satisfaction measures not fed back } \\
\text { directly to projects }\end{array}$ \\
\hline
\end{tabular}




\subsection{Analysis of the case study results}

The experience of the case study companies shows that none of them are using the type of mechanism to measure product introduction performance that has been developed by Clark and Fujimoto (28), which has been judged to be the most effective out of those considered by this paper. Although time and resource were measured by all of the case study companies, balanced measures were not used as quality was measured suboptimally, if at all. Furthermore, comparisons did not take place between the performance of individual product introductions.

The reason given for not adopting this sort of performance measurement was that it was too time consuming as current measurement systems could not provide the information required. Two of the case study companies felt that any comparison between product introductions would always be spurious as no two introductions will ever be the same.

Drawing wider conclusions from case studies should always be undertaken with extreme caution. However, the unanimity of findings across a wide range of backgrounds suggests that the case studies may provide evidence of wider trends. The case studies appear to suggest that the industrial experience of product introduction measures is as monitoring tools to get a particular project completed on time and to budget. The role of performance monitors to measure quality of product introduction or to improve performance appears to be neglected.

\section{DEVELOPING EFFECTIVE PERFORMANCE MEASUREMENTS FOR PRODUCT INTRODUCTION}

\subsection{Summary of findings}

The following questions have been addressed in this paper:

1. What criteria should be used to evaluate alternative mechanisms for measuring the performance of product introduction?

2. Which is the most appropriate of existing mechanisms when evaluated against these criteria?

3. Is this mechanism being practically implemented? If not, why not?

General criteria have been taken for the development of effective performance measures and these have been tailored for product introduction. This resulted in the development of the following evaluation criteria for mechanisms for measuring the performance of product introduction:

1. Mechanisms should be aimed at a 'whole-process' level.

2. Mechanisms should be balanced in terms of resource, lead-time and quality.

3. Mechanisms should facilitate performance comparisons across projects.
Reviewing existing mechanisms of performance measurement highlighted the fact that the 'integrated measurement approach' developed by Clark and Fujimoto (28) most closely matched these criteria. However, a review of industrial practice showed that for the companies surveyed a performance measurement mechanism that used Clark and Fujimoto's principles was not adopted. Although the survey was small in size, the unanimity of findings suggest that this experience may be widespread. The survey showed that, while resource and lead-times were successfully recorded, quality was not measured and no comparison of performance across projects took place.

\subsection{Implications for the development of practical and effective performance measurement mechanisms for product introduction}

The case study experience suggests that in order to create effective and practical performance measurement mechanisms the following problems need to be addressed:

(a) the lack of an effective quality measurement mechanism;

(b) difficulties in making comparisons across projects owing to 'system' problems (e.g. lack of computer automation, data inaccuracies) or comparisons perceived as lacking meaning.

\subsubsection{The lack of an effective quality measurement}

The quality of a process is perceived as the extent to which the output of that process matches customer expectations. When quality of product introduction is considered at a generic level, this concept may be difficult to envisage. However, it is possible to convert this to meaningful specific measures. Clark and Fujimoto (28) created a quality index to measure the quality of product introduction of the various automobile projects that they studied. This consisted of several factors including warranty returns in the first 90 days, consumer press reports, an expert panel assessment and a measure of long-term market share. A quality index containing similar elements could be constructed in different industrial environments. To be used on an on-going basis, however, it would need to be formalized and incorporated into the management information system.

It may be true that it will always be difficult to feedback quality measures to product introduction because of the time lag involved, but it may be possible to derive effective interim measures. For example, the cost of the final product could be estimated at the design stage. [Since Corbett (2) argues that 80 per cent of the cost is determined by that stage, this estimate is likely to be comparatively accurate.]

\subsubsection{Difficulties in making comparisons across projects}

Difficulties in making comparisons were ascribed to two factors: 
(a) system difficulties (i.e. lack of computer automation of data, data inaccuracies);

(b) meaningless comparisons (i.e. the perception that making comparisons across projects was like comparing 'apples with pears')

On the whole, system difficulties would not be difficult to solve given an explicit decision to alter the existing management information systems to provide appropriate information. Steps must be taken to formalize and publicize these changes. Gregory (23) criticizes balanced performance measures operating at the macro level within a company for being one-off mechanisms and not a management process.

Making comparisons between different product introductions may perhaps be a more difficult problem to solve. Some of the case study companies put forward the argument that the difficulties in attempting this were insuperable. Clark and Fujimoto (28) again put forward a way, in the automobile industry, of making these comparisons. They constructed a rating which comprised an assessment of, among other factors,

(a) the unique parts ratio,

(b) the number of pioneering components and

(c) the number of in-house engineering components,

and used this to adjust the raw performance figures for each project. A similar exercise could be carried out for other specific industrial sectors. However, there will always be an element of subjectivity in adjusting raw performance scores.

Comparing raw performance scores across projects without any adjustment can also be an interesting exercise. If two product introductions of what are perceived as similar products give vastly different performance measures then further investigation may be worthwhile.

Creating practical and effective performance measures for product introduction will require some resources. Generic categories will need to be converted to specific industry sector performance measurements and formally incorporated into the existing management information systems. This is a vital exercise if product introduction performance is to be judged on explicit criteria and not management intuition.

\section{ACKNOWLEDGEMENT}

The authors would like to acknowledge the support of EPSRC for the SIMPLOFI (Simultaneous Engineering through People, Organisations and Functional Integration) Project, GRJ43048, of which this work forms a part.

\section{REFERENCES}

1 Wheelwright, S. C. and Clark, K. B. Revolutionizing Product Development, 1991 (Free Press, New York).

2 Corbett, J. Design for economic manufacture. Ann. CIRP, 1986, 35(1), 93-97.

3 Whitney, D. E. Manufacturing by design. Harvard Bus. Rev., July-August 1988, 83-91.

4 Lawson, M. and Karandikar, H. M. A survey of concurrent engineering. Concurrent Engng: Res. Applic., 1994, 2(1), 1-6.

5 Barclay, L. and Taft, J. Trends in new product development and the introduction of simultaneous engineering. In Product Development and Management Association Proceedings, 1992, pp. 66-70.

6 Syan, C. Concurrent engineering practice in the UK: a survey. In Advances in Manufacturing Technology, Vol. VIII (Eds K. Case and S. Newman), 1994 (Taylor and Francis, London).

7 Bihamni, A. Performance measures in UK manufacturing companies: the state of play. Manag. Accounting, December 1993, 20-22.

8 Neely, A., Richards, H., Mills, J. and Platt, K. What makes a 'good' performance measure? In Proceedings of the 2nd European Operations Management Association Conference, Twente, Holland, May 1995, pp. 362-371.

9 Kaplan, R. S. and Norton, D. P. The balanced score-cardmeasures that drive performance. Harvard Bus. Rev., January-February 1992, 71-79.

10 Hise, R., O'Neal, L., McNeal, J. and Parasuraman, A. The effect of product design activities on commercial success levels of new industrial products. J. Prod. Innov. Manag., 1989, 6(1), 43-50

11 Cooper, R. New products: what distinguishes the winners? Res.-Technol. Manag., 1990, 32(6), 27-31.

12 Ayal, I. and Raban, J. Developing hi-tech industrial products for world markets. IEEE Trans. Engng Manag., 1990, 37(3), $177-184$.

13 Weisenfeld-Schenk, U. Technology strategies and the Miles and Snow typology: a study of the biotechnology industries. $R \& D$ Manag., 1994, 24(1), 57-65.

14 Cooper, R. and Kleinschmidt, E. The performance impact of an international orientation on product innovation. Eur. J. Marketing, 1988, 22(10), 56-71.

15 Buggie, F. D. Strategies for new product development. Long Range Plann., 1982, 15(2), 22-31.

16 Stalk, G. Time: the next source of competitive advantage. Harvard Bus. Rev., July-August 1988, 41-51.

17 Azzone, G., Masella, C. and Bertele, U. Design of performance measures for time based companies. Int. J. Prod. Operations Manag., 1991, 11(3), 77-85.

18 Reinertsen, D. G. and Smith, P. G. Developing Products in Half the Time, 1991 (Van Nostrand Reinhold, New York).

19 Turino, J. Management Concurrent Engineering: Buying Time to Market, 1992 (Van Nostrand Reinhold, New York).

20 Marbert, V. A., Muth, J. F. and Schmenner, R. W. Collapsing new product development times. J. Prod. Innov. Manag., 1992, 9(3), 200-212.

21 Sharpe, C. Fresh approach reduces product time to market. Des. Engng, 1991, 26-28.

22 Zahra, S. and Ellor, D. Accelerating new product development and successful market introduction. SAM Advd Manag. $J ., 1993, \mathbf{5 8}(1), 9-18$. 
23 Gregory, M. Integrated performance measurement: a review of current practice and emerging trends. Int. J. Prod. Econ., 1993, 30, 281-296.

24 House, C. H. and Price, R. L. The return map: tracking product teams. Harvard Bus. Rev., January-February 1991, 92100.

25 DTI/CBI National Manufacturing Council. Innovation: The Best Practice, 1993 (DTI, London).

26 Cross, K. F. and Lynch, R. L. The SMART way to define and sustain success. Natl Product. Rev., 1988-9, 8(1), 22-33.

27 Dixon, J. R., Nanni, A. J. and Vollman, T. E. The New Performance Challenge: Measuring Operations for World Class Competition, 1990 (Dow-Jones-Irwin, Homewood, Illinois).

28 Clark, K. and Fujimoto, T. Product Development Performance, 1991 (Harvard Business Press, Boston, Massachusetts).

29 Oliver, N. Design and development benchmarking. In 5th Operations Strategy and Performance Measurement Workshop, Loughborough University, May 1996.

30 Utterback, J., Meyer, M., Tuff, T. and Richardson, R. When speeding concepts to market can be a mistake. Interfaces, July-August 1992, 22(4), 24-37.

31 Crawford, C. M. The hidden costs of accelerated product development. EMR, Summer 1993, 21-28.

32 von Braun, C. F. The acceleration trap. EMR, Fall 1991, $13-19$.

33 Johnson, P. and Gill, J. Research Methods for Managers, 1991 (Paul Chapman Publishing).

\section{APPENDIX}

\section{Details of the company case studies}

\section{Company A}

Company A employed approximately 300 people. It was a manufacturer of large capital equipment for the mining and construction industries. It has five major product lines. These varied from requiring purely parametric design to highly individual and substantial 'one-off' projects. The company's expertise lies in mechanical design: controls were completely 'bought out'. The company had recently restructured its organization to become more project focused. However, this did not extend to the use of multidisciplinary teams for product introduction.

The primary measurements used in assessing the performance of individual product introductions were time and cost. Quality of the product or process was not assessed. The time taken to complete the projects was monitored using automated project planning packages. This task was complicated as the engineering section and the manufacturing section used different packages. A manual interface was required between the two. The performance to plan was monitored by the project manager. Cost performance was measured by an automated work-booking system where employees in both the engineering and manufacturing sections booked their time against a particular product introduction. These figures were then used to create utilization information for the engineering section.
Cost performance was measured separately to time performance at different monthly meetings.

No comparisons between individual project performances were made and no aggregate performance figures (such as the utilization figures generated by the automated workbooking system) were used in planning. This was left to an individual manager's estimation. Because time and cost information was automated, comparisons could have been possible but the company did not perform this and gave the following reasons for not doing so.

The sample was 'statistically too small'. The company argued that as it performed few new product introductions in a year (less than 20 across all product lines), there were too few occurrences for any meaningful trend to emerge.

Data inaccuracies. The company did not have confidence in its automated work-booking system. It was felt that booking to the wrong project was taking place and that this invalidated the cost information provided by the work-booking system in some cases.

Inability to make comparisons across projects. The company argued that no two design projects were ever the same and that therefore making any comparisons between them would be very difficult.

It is interesting to note that the raison d'être for changes in the organization for product introduction was not to improve aggregate levels of performance in terms of time or cost. The reasoning behind these changes had been to 'change philosophy', 'improve coordination' and 'facilitate downsizing'.

\section{Company B}

Company B has approximately 200 employees. It manufactures large material handling devices. It manufactures only one product line and these are specifically designed for the individual. Company B has also made recent significant changes to its product introduction organization. It has created engineering teams headed by a project manager that focus solely upon the design of individual projects. Manufacturing, purchasing, electrical engineering and other disciplines involved in product introduction do not form part of the team.

Performance measures for individual projects were used in Company B that related to lead-time, cost and quality. Lead-time was measured against a project plan. Cost was evaluated in terms of hours and materials as every new product manufactured was in effect a product introduction. Some estimation of quality was measured by recording warranty costs, but until very recently this had not been allocated to a specific project. Traditionally, performance measurements had been generated manually. All of this information was then held in a physical 'project file'. Two moves to change this mechanism had been recently initiated. 
The introduction of visible performance measurements. The company had recently introduced a 'team' method of working throughout the organization. Each team inhabited what was known as a 'green area'. In each 'green area', simple, visible performance measures of the teams' activity were required for display. In 'new' product introduction 'green areas', these consisted of Gantt charts of time-scales and 'actual' versus 'budget cost' diagrams.

The introduction of a combined project planning and accounting system. The company introduced a new package that not only replaces the former accounts packages but also incorporated work-booking and project planning.

All of the performance measures were monitored informally by the general manager. No attempt was made to generate aggregate measures of performance or to make comparisons between individual project performance measures. Company B gave the following reasons for not making performance comparisons:

1. Historic cost information was inaccurate. The cost information held on the old accounting system was judged to be inaccurate as it had suffered from a number of workbooking errors.

2. Historic lead-time information was difficult to access. Historic lead-time information was held in manual project files. These were large documents with no standard format and therefore retrieving any information from them was time consuming and difficult.

3. Dissimilarity of projects. The company maintained that individual projects, despite being for the same product in broadly similar applications, were sufficiently dissimilar to make comparisons not worthwhile.

\section{Company $C$}

Company $\mathrm{C}$ has approximately 200 employees. It manufactures railway equipment. Products are designed for a specific customer but thereafter have repeat orders either from the same or other customers. The company has again recently restructured its product introduction system. It has divided the types of new products that it introduces according to the degree of innovation that they involve. It has introduced different structure and processes to deal with the different types of product introduction.

The performance measures used for individual projects are lead-time and cost. Lead-time is measured against initial project plans. Cost is calculated on work-hours and external development expenditure basis. Quality of product introduction was not measured in any way. No automation was in place for measures of product introduction performance. The company accounts package could only recognize on-going production. (This, in effect, meant that Company $\mathrm{C}$ had no automated means of knowing whether a project was on budget or not.) The company stipulated in its procedures that manual measure of performance information on cost and time should be held in a project file. These should be held in a specific geographical location, with a given format and updated according to specific procedures.

The company made no comparisons between product introduction performance for different projects and no aggregate measures of performance. Company $\mathrm{C}$ thought that this may be a worthwhile exercise but, without automation, thought that this would be too time consuming. Company $\mathrm{C}$ undertook a one-off investigation to attempt to compare cost and lead-time information across a sample of recent products. In each case the manual performance information was not found in its prescribed location and any information that was available was not formatted in a uniform fashion. Company $\mathrm{C}$ thought that its sample was probably representative of most performance measure information.

\section{Company D}

Company D has approximately 400 employees. It manufactures materials testing equipment and operates mainly in a 'design-to-forecast' environment. It has a small customization operation. The company has recently introduced multidisciplinary, concurrent engineering teams to perform its product introduction. These teams, however, are not fulltime or co-located.

Performance measures used by Company D are lead-time (obtained from an automated project planning system), engineering hours (obtained from an automated work-booking system) and quality in terms of meeting a target product cost. 'Voice-of-the customer' campaigns and field reports provide other quality information but no system directly links these back to a particular product introduction. The existing planning and work-booking systems are about to be replaced by integrated planning systems.

Company D performed no comparisons on performance between product introductions and did not produce any aggregate measures of performance. However, comparison exercises were considered possible and worth while by the company.

\section{Company E}

Company E was much larger than any of the other companies surveyed in this exercise. It employs approximately 40000 employees and operates in the automotive industry. It works on an entirely 'design-for-forecast' basis. Company E introduced full-time co-located project teams that were entirely responsible for the introduction of new products. However, more recently, it has felt the need to assert some degree of 'function' once again within its organizational structure.

The measures used in Company E for assessing product introduction performance are lead-time and cost. Product introductions for Company E represent vast projects requiring resources of the order of $£ 200$ million. It is unsurprising in these circumstances that expenditure is monitored very closely. Company $\mathrm{E}$ has a series of large corporate automated systems to perform these functions. However, 
Company E still finds it difficult to assemble a total project figure. For example, manufacturing engineering expenditure is accounted for under operation and is not allocated to a particular product introduction. A similar situation exists with a capital spend for developmental purposes. Total progress for individual product introductions is pulled together on a monthly basis at headquarters but this is partly a paper exercise. Quality of product introduction is measured through examination of warranty returns and customer satisfaction exercises. However, this is not directly related to a particular project.

Company E carries out very limited comparisons between product introduction. Any comparisons that do take place occur at the 'macro' level that make tracing the reasons for these differences and attempting to remedy them very difficult. One-off exercises at a more 'micro' level have been undertaken but these prove to be time consuming in gathering the relevant information together. 